Liszkowski, U. \& Ruether, J. (2021). Ontogenetic origins of infant pointing. In: Nathalie Gontier, Andy Lock, and Chris Sinha (Eds.). The Oxford Handbook of Human Symbolic Evolution.

\title{
Ontogenetic origins of infant pointing
}

\section{Ulf Liszkowski and Johanna Rüther}

Human pointing is foundational to language acquisition and sociality. The current chapter explores the ontogenetic origins of the human pointing gesture in infancy. First, the authors define infant pointing in terms of function, cognition, motivation, and morphology. Then, the authors review current evidence for predictors of infant pointing on child and caregiver levels, because any predictors provide insights into the basic developmental factors. From this review, the authors introduce and discuss a number of pertinent accounts on the emergence of pointing: social shaping accounts (pointing-fromreaching; pointing-from-non-communicative pointing) and social cognition accounts (pointing-from-imitation; pointing-from-gaze-following). The authors end by presenting a synthesis, which holds that child-level cognitive factors, specifically directedness and social motivation, interact with caregiver-level social factors, specifically responsiveness and assisting actions relevant to infants' directed activity. The interaction of these factors creates social goals and formats that scale up to pointing acts expressing triadic relations between infant, caregiver, and entities at a distance in the context of joint activity and experience.

Keywords: gesture, language, constructivism, social cognition, responsiveness, infancy

\section{Introduction}

Humans communicate with each other in unique ways. This is not just because of language. Rather, humans possess unique social-cognitive skills which enable the 
meaningful use of language and other forms of communication. This cognitive basis is operational before infants acquire language, and foundational to language acquisition (Tomasello, Carpenter, \& Liszkowski, 2007). Research on prelinguistic infants' use of the non-verbal pointing gesture has been most revealing in this respect. Experimental evidence from the past decades has demonstrated that around their first birthdays, before they use language in earnest, infants point meaningfully to intentionally refer others to entities and events for a variety of reasons (for a review of the evidence, see Liszkowski, 2018). The ontogenetic advent of pointing takes on "cosmic importance" (Bates, 1979) for further linguistic and social cognitive development (Capirci et al., 1996; Iverson \& Goldin-Meadow, 2005; Sodian \& Kristen-Antonow, 2015); the aberrant development of pointing is a key symptom of autism (Baron-Cohen, 1989); and the usage of pointing is unique to humans in several ways (Tomasello, 2006; Liszkowski, 2018). Surprisingly, however, little empirical research has addressed the ontogenetic origins of pointing itself. In the current chapter we therefore ask: what leads to human pointing?

In the next section ("Infant pointing"), we characterize infant pointing in terms of its function, cognition, motivation, and morphology, to provide a definition of the behavior that we wish to predict. In "Predictors of infant pointing," we then review what is known empirically about developmental predictors of infant pointing. The section "Theoretical views on the emergence of infant pointing" presents and critically discusses theoretical accounts of the ontogeny of pointing. We end with the section "The multifaceted roots of infant pointing" by presenting our synthesis account on the emergence of pointing in accordance with recent findings.

\section{Infant pointing}

What leads to human pointing? To address this question, we need to have a grasp of the end point of development we want to predict. Because mature pointing is a multifaceted 
behavior, we need to take several characteristics into account. Here, we focus on the function, cognition, motivation, and morphology of pointing behavior. Functionally, pointing is not an individual activity but serves a regulatory social-communicative function to enable coordinating with other persons' actions, feelings, and thoughts by directing their attention to relevant aspects in a shared environment (Brink, 2004; Sperber \& Wilson, 1986). Cognitively, then, pointing requires an understanding of other persons as intentional agents with conative and epistemic states; and a flexible, intended use of the gesture across a variety of social contexts. Motivationally, pointing is thus not limited to one purpose but instead incorporates several social motives, like requesting, helping, affiliating, perhaps akin to distinct speech act types (Bates, Camaioni, \& Volterra, 1975). In addition, we need to consider the morphology of pointing which differs across situations and cultural conventions, ranging from hand-pointing to index-finger pointing to lip-pointing (e.g., Enfield, 2001). Importantly, the behavior we want to predict should itself be predictive of language and social understanding for it to be indeed of relevance as foundational behavior. In quest of the origins of pointing, we are thus looking for the roots of a behavior that is foundational to human language and sociality.

Clearly, any account on the emergence of pointing faces the challenge of failing to account for all of the various characteristics of human pointing. In characterizing and investigating pointing, research has often focused on different aspects. For example, the isolated index-finger extension of three-month-olds is sometimes called "pointing" (Hannan \& Fogel, 1987), but the behavior lacks the key functional components of pointing, notably the attempt to direct attention (see Figure 31.1). Other accounts focus on whole-hand pointing (Leavens \& Hopkins, 1999; Vygotsky, 1962), which is different in form from infants' typical index-finger pointing shape found across diverse cultural settings (Liszkowski et al., 2012), see Figure 31.2. Yet other researchers focus on index- 
finger pointing, but as an individual non-communicative activity, like touching behavior (Carpendale \& Carpendale, 2010; O’Madagain, Kachel, \& Strickland, 2019). Many researchers define the communicative component of pointing by the accompanying characteristic of gaze checking with the recipient (Carpenter, Nagell, \& Tomasello, 1998; Matthews, Behne, Lieven, \& Tomasello, 2012). But a lack of mutual gaze checking is not evidence for the absence of communicative intent. Conversely, mutual gaze checking may also happen for reasons other than communication (e.g., to check when something unexpected happens; Liszkowski, Carpenter, Henning, Striano, \& Tomasello, 2004; Lock, Young, Service, \& Chandler, 1990). In routine settings (e.g., on parents' arms, see Figure 31.2) gaze checking may not be necessary at all. Finally, other researchers have focused on one kind of motivation of pointing, often the request-making purpose of pointing (Camaioni, 1993; Vygotsky, 1962), which is shared with nonhuman primates (Call \& Tomasello, 1994) and also appears intact in children with autism (Baron-Cohen, 1989), but fail to account for other, prosocial motivations underlying human pointing early in typical development, like sharing experience or helpfully providing relevant information.

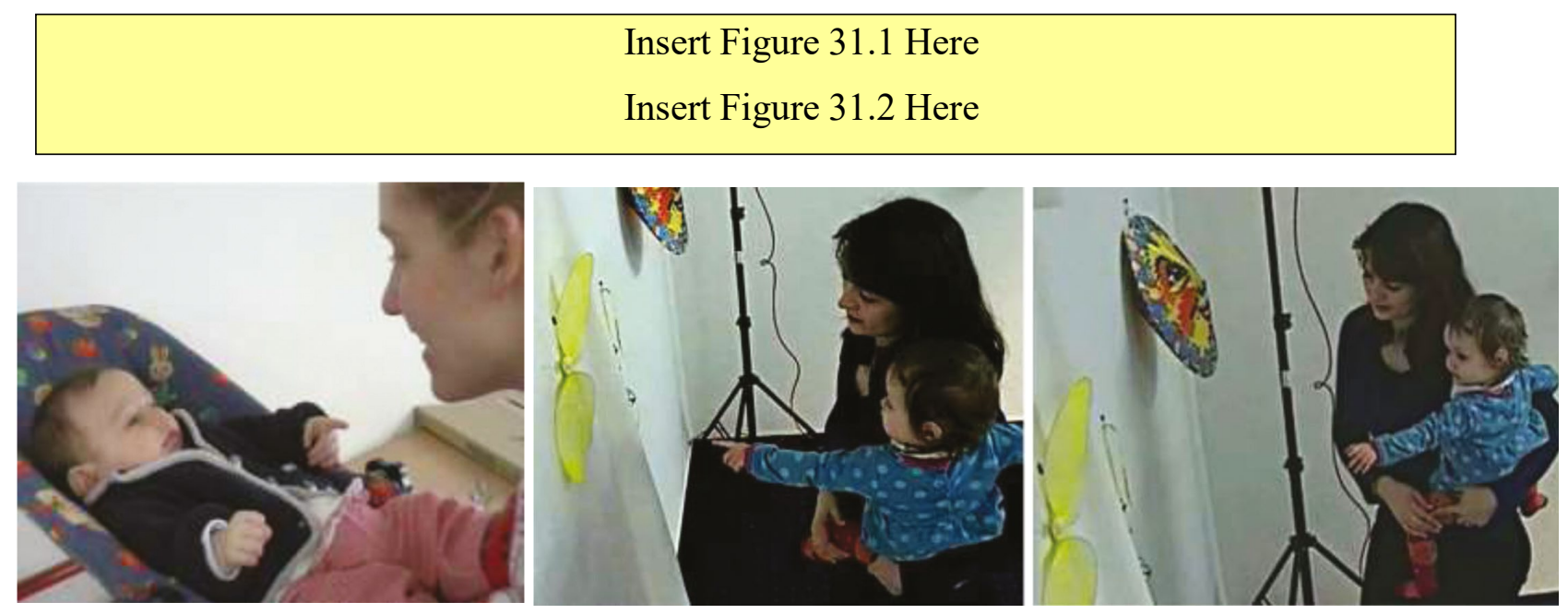

What behavior, then, do we mean by infant pointing, and how do we operationalize it in order to predict its ontogenetic emergence at a given age? Crosssectional research on the communicative and cognitive complexities of infant pointing, 
and longitudinal research using pointing as a predictor for language acquisition have been helpful in providing an answer. Regarding communicative and cognitive complexity, experimental evidence shows that by twelve months of age, infants' pointing is a communicative, referential act, used flexibly across a range of situations for various purposes (Liszkowski, 2018, for an overview). The findings show that infants' pointing involves an understanding of others' intentions, attention, and knowledge states, both in production and comprehension, with correlations between referential pointing and point comprehension at twelve months of age (Behne, Liszkowski, Carpenter, \& Tomasello, 2012; Liszkowski \& Tomasello, 2011). In sum the evidence reveals that the key components of human pointing in terms of function, cognition, and motivation are present by twelve months of age.

Regarding the morphology of pointing, infants in those experiments predominantly used the canonical pointing gesture with the extended index-finger relative to all other fingers, often (not always) with the other fingers curled into the palm, and with an outstretched unsupported arm directed at identifiable items distal from the finger, typically well out of reach (Franco \& Butterworth, 1996; Grünloh \& Liszkowski, 2015). Index-finger pointing thus defined emerges around the median age of eleven to twelve months (Carpenter et al., 1998; Liszkowski \& Tomasello, 2011; Lock et al., 1990) as a universal form of human pointing (Liszkowski et al., 2012). Subsequent correlational research has established that twelve-month-olds who point with the index-finger are significantly better compared to twelve-month-olds who point only with the open hand at social-cognitive tasks requiring the comprehension of referential intentions (Liszkowski \& Tomasello, 2011). Further, the index-finger shaped pointing gesture, not whole hand pointing, is predictive of later language acquisition (Lüke, Grimminger, Rohlfing, Liszkowski, \& Ritterfeld, 2016). And twelve-month-olds who point with the index-finger point more often and accompany their pointing more often with vocalizations compared 
to twelve-month-olds who only point with the whole hand (Liszkowski \& Tomasello, 2011). Accompanying vocalizations of index-finger points are further more speech-like than those vocalizations accompanying whole hand points (Grünloh \& Liszkowski, 2015).

Interestingly, blind children who do indicate directions gesturally, make these indications with the open hand, flat palm, not with the isolated index-finger extended (Iverson \& Goldin-Meadow, 2001). And when zoo-housed apes point to request from human keepers (Call \& Tomasello, 1994; Leavens \& Hopkins, 1999), they typically move as close as possible or necessary to the desired item to successfully signal their action intent, sometimes by extending the index-finger through the caging toward the item (Leavens, Ely, Hopkins, \& Bard, 2012). The caging hinders apes to touch and grab the item, but they can use the action schema to signal their individual intention to a cooperative keeper. In contrast, human twelve-month-olds point to communicate their referential intent with the extended index-finger from a distance to accessible items to which they could easily crawl or walk, sometimes even when these are in reach and couldbe grabbed (van der Goot, Marloes, Tomasello, \& Liszkowski, 2014).

In sum, these findings converge to show that we need to look for predictors of index-finger pointing when it emerges around twelve months of age as a communicativereferential act. However, scrutiny is required in differentiating index-finger pointing from simple index-finger extension, from proximal index-finger touching and exploration, and from other, non-communicative usage.

\section{Predictors of infant pointing}

Before infants become communicative-referential index-finger pointers around twelve months of age, they exhibit several other communicative behaviors that share some 
aspects of communicative-referential pointing. They hold out objects, perhaps to show or offer these (around eight to ten months; Bates et al., 1975; Cameron-Faulkner, Theakston, Lieven, \& Tomasello, 2015); they reach for out-of-reach items when someone is around to help them (around eight months; Ramenzoni \& Liszkowski, 2016); they point with the open hand (from around six to eight months; Lock et al., 1990); they orient their own attention to items and explore them with their index-finger (Butterworth \& Morissette, 1996; Carpendale \& Carpendale, 2010); and they vocalize with intonations that reveal communicative intent (at seven to eleven months; Esteve-Gibert \& Prieto, 2013). All these behaviors suggest that communicative index-finger pointing does not mature independently but is likely based in one or another way on these and other earlier behaviors and antecedents. At the same time, none of these earlier behaviors seem to correspond in all aspects of quality to the unique form of human referential communication as when infants point with the extended index-finger around twelve months of age.

What, then, could predict the emergence of infants' communicative referential index-finger pointing acts? Before we review relevant empirical findings, it is useful to briefly systematize possible factors. Broadly, we can differentiate between predictors on the child level, and predictors on the caregiver level, and how they interact in development (see Figure 31.3).

\section{Insert Figure 31.3 Here}

\section{Figure 31.3:}

Factors predicting the age of emergence and/or frequency of infant pointing on the child level and the caregiver level. Arrows symbolize mutual interactions between factors and levels. 


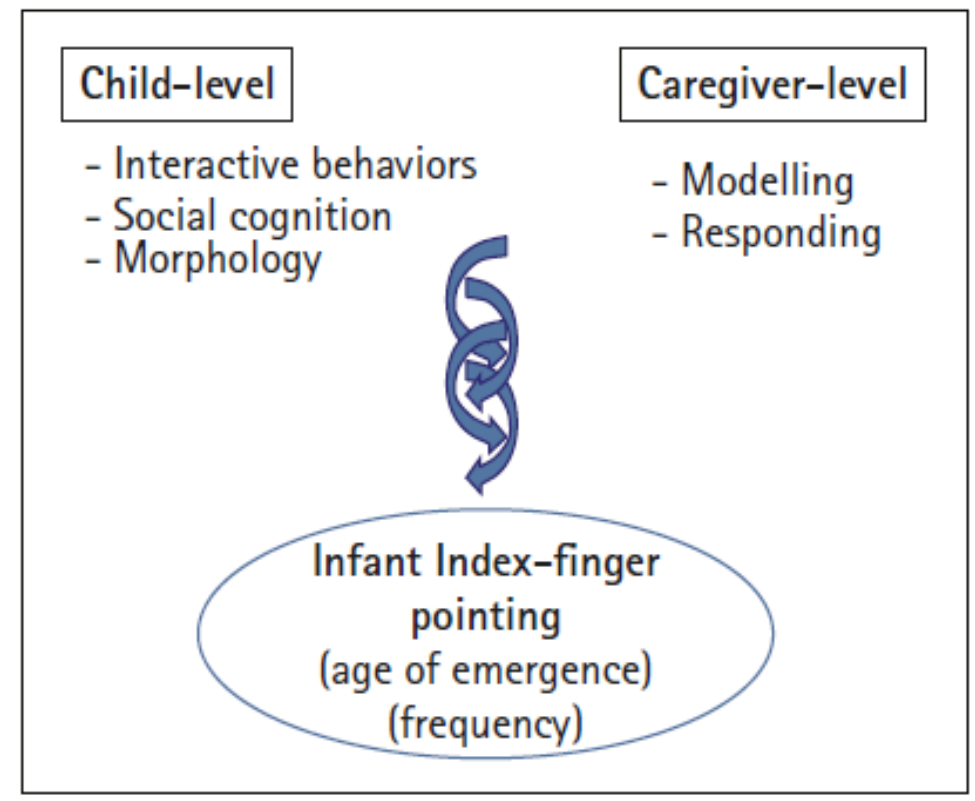

On the child level, we can differentiate between social-interactional, cognitive, and morphological predictors. Accordingly, there should be social-interactional precursor behaviors that share some (but not all) of the features of the interactional quality of infants' pointing acts. And there should be cognitive precursors to the cognitive underpinnings of communicative referential pointing acts. And there may be morphologically similar, earlier emerging behaviors that are related to the outstretched arm and extended index-finger.

On the caregiver level, we can distinguish between modeling behavior and responsive behavior. Regarding the former, a predictive factor would be how caregivers model the relevant behavior, i.e., pointing, for their infants. Regarding the latter, a predictive factor would be how caregivers respond to infants' behavior, and how this in turn then shapes up a new behavior in infants. Naturally, in development, infant and caregiver behaviors are intertwined at any moment in time such that a given precursor on one level may as well be a resulting consequence from the other level, with development proceeding in a dialectic manner, as anticipated by social-constructivist theories of development (Bruner, 1983; Vygotsky, 1978; for recent research on language 
development, see, e.g., Renzi et al., 2017; Wu \& Gros-Louis, 2014; Chang, de Barbaro, \& Deák, 2016).

Careful natural observations of interactional settings are thus a necessary and useful basis for further systematic investigation (Carpendale, Atwood, \& Kettner, 2013; Lock et al., 1990). However, to identify causal predictors of pointing and how they may interact in development, it is necessary to assess each of these at a group level at several moments in time and analyze longitudinal correlational patterns and interrelations to obtain a picture of their longitudinal interrelations. Ultimately, experimental manipulations of single factors at varying moments in time could tell their ordered causal impact on the emergence of pointing.

A subtle but important distinction concerns the prediction of the onset of the gesture versus the frequency with which it is then used. The age of onset relies perhaps more on child-level capacities, while the frequency with which pointing is then used likely relies in addition on the opportunities provided by the social-interactive environment within which it can be employed (see Puccini et al., 2010). Certainly, both variables may be continuously related throughout development, for example, an early onset may be positively related to later frequent use (Butterworth \& Morissette, 1996).

\section{Child-level predictors}

\section{Interactive behaviors}

Infants show several interactive behaviors before they become index-finger pointers. Two main behaviors are of focal interest, because they share some crucial elements of pointing: showing and reaching. The showing gesture emerges several months before infants begin to point (Bates, Camaioni, \& Volterra, 1975). Infants lift objects when interacting with others in a seeming attempt to bring these to the interactant's focus of 
attention. Conceptually, this kind of showing behavior appears to be very similar to pointing behavior, if it directs attention to an object. Empirically, however, it has remained unclear to date whether infants rather want to obtain attention to themselves when they lift the objects they act on ("show off;" Bates et al., 1975), or whether they truly want to refer the other to the objects of their interest. This distinction has been settled for the case of twelve-month-olds' pointing, which clearly is referential (Liszkowski et al., 2004, 2006, 2007a, b), but remains to be tested for pre-pointing infants' use of the showing gesture.

Two recent studies have analyzed the showing gesture in more detail with regard to its predictive value and its interactional quality (Boundy, Cameron-Faulkner, \& Theakston, 2016; Cameron-Faulkner et al., 2015). Because it is notoriously difficult to distinguish whether infants want to show, offer, or give an object, the researchers have grouped these behaviors under the term "hold-out and give gestures (HoGs)". Analyzing lab-based free play interactions with their caregivers, the authors found that the number of infants' HoGs at ten and eleven months is positively correlated with the amount of index-finger pointing at twelve months of age. Further, while subtle kinematic differences may allow a statistical distinction between "hold-outs" and "gives," parents' responses to "HoGs" do not necessarily align with this distinction, revealing that parents will often interpret a show as an attempt to give, and vice versa. The rather subtle differences in these behaviors may suggest either that infants do not yet clearly differentiate their use; or that they do differentiate, but that parents' adequate responses are not a necessary requirement for infants' use. In the absence of empirical evidence on the cognitive underpinnings and infants' expectations of responses, it is currently difficultto tease apart these possibilities. However, the findings demonstrate empirically that the showing (or $\mathrm{HoG}$ ) gesture does have predictive value for the later use of the pointing gesture. Interestingly, despite a literature on zoo-housed apes' pointing, apes 
have not been reported to regularly show objects they hold in their hands to others, substantiating the view that different processes underlie ape and human infant pointing.

Another important behavior is reaching, which emerges early in the first few months of life (Lobo \& Galloway, 2013). While reaching-to-grasp is an instrumental noncommunicative act, infants will begin to reach for out-of-reach objects, and this act may indeed share some of the communicative and referential aspects of pointing. Conceptually, this kind of reaching gesture to out-of-reach objects has been taken to direct others' attention to a desired object, and to incorporate a deictic quality of pointing (e.g., Blake, O'Rourke, \& Borzellino, 1994). Alternatively, however, infants' reaching may derive from ritualized action and involve a cognitively simpler expectation that the abbreviated action is sufficient to spur the recipient into action (Bruner, 1975). Indeed, apes' food-begging gestures, and zoo-housed apes' reaching gestures to cooperative keepers may be of that origin and involve similar cognitive processes. A recent experimental study with infants (Ramenzoni \& Liszkowski, 2016) reveals that eightmonth-olds selectively reach for out of reach objects when a helpful person is present compared to when they are alone, suggesting that by eight months infants use their instrumental action schema for social-interactional purposes. Indeed, caregivers of eightmonth-olds report interpreting reaching as requests for objects and typically assist infants in attaining their goals (Reilly et al., 2006). One possibility, which we discuss and endorse at the end of the current chapter is that showing and reaching gestures are an integral part of complementary give-and-take routines which emerge sometime around that age (Hay \& Murray, 1982; Messinger \& Fogel, 1998). However, the presence of reaching behaviors in non-human apes, and in children with autism, who do not develop typical forms and use of pointing, suggests that reaching in itself is not sufficient to lead to human forms of pointing. 


\section{Social cognition}

A key element of communicative-referential pointing is the understanding that it directs attention to a shared focus. An understanding of others' attentional states is typically assessed with gaze- and point-following tasks (e.g., Brooks \& Meltzoff, 2002), and indeed point production and comprehension are correlated at twelve months of age (Behne et al., 2012; Liszkowski \& Tomasello, 2011). One common finding is that infants begin to follow others' attention sometime around six to nine months of age (Carpenter et al., 1998; D'Entremont, Hains, \& Muir, 1997), before they direct others' attention with pointing, although point-following also appears to improve once infants begin to point (Ger, Altınok, Liszkowski, \& Küntay, 2018; Leung \& Rheingold, 1981). A recent study found a longitudinal relation between the amount of point-following at nine to eleven months and the amount of index-finger pointing a month later (Matthews et al., 2012). On the other hand, nonhuman primates (and dogs and goats) follow others' attention (Tomasello, Hare, Lehmann, \& Call, 2007), which suggests that following attention in itself is not sufficient to lead to human forms of referential index-finger pointing.

\section{Morphology}

Infants extend the isolated index-finger early after birth (e.g., Hannan \& Fogel, 1987), and an unsystematic check of publicly available three-dimensional ultrasound pictures in the worldwide web suggests that infants can do so already in utero. Masataka (2003) has suggested that young infants extend the index-finger more often in arousing situations, and that parents are likely to respond with speech-like vocalizations to index-finger extension, treating it as communicative (see Figure 31.1. For a social effect of indexfinger extension, see also Rönnqvist \& von Hofsten, 1994). Carpendale \& Carpendale (2010) report a mother's observations of her child extending the isolated index-finger during nursing, and in bed with eyes closed, which suggests that index-finger extension 
occurs in a wide variety of contexts and by itself likely does not lead to a very specific environmental response. Around eight months, infants develop fine motor skills to touch and manipulate small objects with the extended index-finger and the pincer grip, which could be one key element of pointing (Butterworth \& Morissette, 1996; O'Madagain et al., 2019). Apes, however, can also use the pincer grip and use the index-finger to touch small food items suggesting that index-finger extension and touch-exploration itself are not sufficient to lead to human referential index-finger pointing (Butterworth \& Itakura, 1998; Hopkins, Cantalupo, Wesley, Hostetter, \& Pilcher, 2002). Further, infants (and adults) also extend the arm and hand without the extended index-finger, not just to reach but seemingly also to point. This type of hand pointing precedes index-finger pointing ontogenetically, and it persists in the repertoire after index-finger pointing has emerged (Liszkowski \& Tomasello, 2011; Lock et al., 1990).

\section{Caregiver-level predictors}

\section{Modeling behaviors}

Caregivers point for their infants. Few studies, however, have investigated whether it has predictive value for the emergence of infant index-finger pointing. Several studies have revealed synchronic correlations between the amount of caregiver and infant pointing at fourteen months (Rowe \& Goldin-Meadow, 2009); at twelve months (Liszkowski \& Tomasello, 2011); and in a cross-culturally diverse sample of infants between ten to fourteen months (Liszkowski et al, 2012). A further study (Salomo \& Liszkowski, 2013) shows that age-matched eight-to-fifteen-month-old infants of three cultural groups vary in the amount of pointing as a function of caregivers' amount of deictic attention directing gestures. The study shows that the onset of index-finger pointing co-varies with cultural group, suggesting that caregiver gestures are a mediating factor in the emergence of index-finger pointing, given the natural quasi-experimental design of the study. 
Two further studies have employed training designs. Marcos (1991) used a microgenetic method and instructed mothers of twelve- to thirteen-month-old infants in an experimental group to engage as much as possible in referential exchanges with their infants about the same poster across three sessions. In a subsequent test session infants pointed significantly more compared to a control group. The author suggests that through the process of conventionalization infants increase their pointing (among other referential behaviors) - they are socialized into referring to things in a given situation. However, while this study demonstrates an impact of parental pointing on the amount of infant pointing, it does not speak to the emergence of pointing itself, because infants were already twelve to thirteen months old and presumably, many could point already at the beginning of the training.

Matthews et al. (2012) instructed parents of a training group of nine-to-elevenmonth-olds to point for their infants at home during a one-month interval. In comparison to a control group there were no increased levels of infant index-finger pointing a month later during a lab visit. The authors found a slight difference between the groups in the onset and frequency of index-finger pointing with gaze checking, and suggest that the gaze-checking component of pointing, not pointing itself, may be socialized. Different to the Marcos (1991) study, Matthews et al. (2012) did not use the same situation during training and test. The absence of a training effect could suggest that infants do not generalize pointing training across contexts. Matthews et al. (2012) further reported a longitudinal correlation between parents' pointing during free play at time one and the pointing of their infants during a different, experimental situation two weeks later, suggesting a somewhat more situation-general relation between parent and infant pointing. However, since infants' pointing was not assessed concurrently to parents' pointing at time one, the correlation remains amenable to an interpretation of a synchronic rather than diachronic relation (see also Rowe \& Leech, 2018). 
Taken together, findings to date thus suggest that there is a relation between caregiver and infant pointing, with some indication that modelling may impact the amount of pointing gestures infants will use. While the cross-cultural differences also indicate that the emergence of pointing itself is socially mediated (Salomo \& Liszkowski, 2013), it remains unknown from these natural quasi-experimental data what aspects of the social environment would best account for this effect, specifically whether it is the modelling part of pointing or some other responsive behaviors of caregivers.

\section{Responsiveness}

Caregivers typically respond to their infants' behaviors. When infants show an object, caregivers will often attempt to take it (Cameron-Faulkner et al., 2015; Hay \& Murray, 1982); when infants reach for an object, caregivers will typically offer it; and when infants point, caregivers will typically comment on the referent (Marcos, 1991; for indexfinger pointing: Kishimoto et al., 2007; Kishimoto, personal communication with author). Research shows that caregivers' contingent responding to infants' babbling increases babbling behavior (Goldstein \& Schwade, 2008). One question is whether contingent responses to pointing increase pointing. Murphy (1978) reported observations of socalled "pointing chains" in which caregivers and infants pointed alternately to pictures in a picture book. Liszkowski et al. (2012) found that the numbers of contingent responsive points between parents and infants were highly interrelated, revealing a strong effect of responsiveness on referential communication. Kishimoto (2017) further found that caregivers' contingent responsive points to infants' points developmentally predicted the increase in infant pointing across the second year. In a recent study, Ger et al. (2018) found that specifically those responses by parents to infant pointing which contained referential uptake - in contrast to any other contingent response - were longitudinally predictive of an increase in the amount of pointing from ten to twelve months of age. 
The findings provide further evidence for pointing as a joint communicative activity distributed across participants Most of the reported relations between infant and caregiver, however, are synchronous, and based on responses to pointing behavior once it has already emerged. While the findings on interlocutors' referential responses provide further support for the role of socialization, they do not speak to the very emergence of referential pointing. To be predictive of the emergence of pointing, we have to look at caregiver responsiveness to behaviors prior to pointing. There is currently little evidence for it, but as we will argue, reactions to showing and reaching behaviors would seem prime candidates (Hay \& Murray, 1982). Essentially, both involve the transposition of objects, and in both cases, this transposition is not just of a physical nature but instead richly social. Infants' show gesture lends itself to caregivers' referential interpretation of it, as an offer, before then taking (or admiring) the object; and infants' reaching likely leads to caregivers' referential offer of the object (gloss: “this one?"), before handing it over (see later, section entitled "The multifaceted view of social pointing" for elaboration; and Figure 31.4).

\section{Theoretical views on the emergence of infant pointing}

The past decade has yielded a wealth of new empirical findings on how and why infants point, and new findings about the various factors in the emergence of pointing are accumulating. We now turn to review and discuss existing theoretical views about the ontogenetic origins of pointing. We do so in an attempt to provide a synthesis of the various accounts and present our own view in the next section.

About thirty years ago, Lock et al. (1990) concluded their chapter about infant pointing by stating, "its origins are not straightforward (Lock et al., 1990, p. 55)". Indeed, none of the views we discuss next can fully account for all aspects of the emergence of pointing. Most pertinent in the literature are ideas that pointing emerges from reaching; or 
is socialized from non-communicative pointing; or learnt via imitation (Lock et al., 1990). These three views have in common that they acknowledge the important role of the social environment in the emergence of pointing. However, they differ quite strongly in their emphasis on external environmental forces on the one hand, and internal cognitive processes on the other hand. The first two views take interactions with the infant as the main driving force (henceforth social shaping accounts), while the latter view emphasizes cognitive processes as the main driving force, which enable infants to participate in, and benefit from, interactions with others (henceforth social cognition accounts).

\section{Social shaping accounts}

The two most pertinent social shaping views are that pointing derives from reaching and that pointing derives from non-communicative pointing. The common key assumption of both these accounts is that a given infant behavior is transformed through caregivers' reactions into a new use of that behavior. Table 31.1 displays three necessary steps entailed in social shaping accounts.

\section{Insert Table 31.1 Here}

\section{Table 31.1:}

Three steps in social shaping accounts of how the use of behavior is transformed

\begin{tabular}{ll}
\hline Step 1 & $\begin{array}{l}\text { A regular infant behavior, which is not the target behavior (here: not communicative } \\
\text { pointing) in that it is not intended to bring about the caregiver reaction to the target behavior. }\end{array}$ \\
\hline Step 2 & $\begin{array}{l}\text { Caregivers react consistently to infants' behavior in Step 1, as if infants intended to bring } \\
\text { about caregivers' reaction. }\end{array}$ \\
\hline Step 3 & $\begin{array}{l}\text { Caregivers' reaction leads infants to a new use of the old behavior, now with the intention to } \\
\text { bring about the caregivers' consistent reaction. }\end{array}$ \\
\hline
\end{tabular}




\section{Pointing from reaching}

Vygotsky (1962) suggested that pointing derives from reaching. In a process of ontogenetic ritualization (see Lock et al., 1990) caregivers anticipate the goal of infants' grasping and offer the objects to infants. Infants, in turn, learn to anticipate caregivers' responses to their grasping and so begin to use the reaching-to-grasp action schema to request out-of-reach items. In the shaping sequence, step 1 (infant behavior: grasping) and step 2 (caregiver consistent reaction: giving) are thus fulfilled. There is also evidence for step 3 of the shaping sequence, the transformation of an initially non-communicative behavior (reach-to-grasp) into an intended social-communicative behavior (reach-tosignal). While six-month-olds know what they can and cannot reach, and refrain from reaching when the object is too far away (Rochat, Goubet, \& Senders, 1999), by eight months they reach for out-of-reach objects selectively in the presence of an adult who canhelp achieve the goal (Ramenzoni \& Liszkowski, 2016). Thus, when they reach for out- of-reach objects, infants use their reaching action schema to spur someone else into action in expectation of being helped.

The problem with this account is that the resulting behavior is not the kind of "pointing" we are looking for. Specifically, the problem is on the motivational level. Infants point to share interest in a variety of things they do not want to obtain but rather want the other to attend to and comment on (Liszkowski et al., 2004, 2007b). Sometimes the referents are even physically impossible to reach (e.g., point to a sound (Bates et al., 1975); or to an airplane in the sky). Further, infants helpfully point to inform a person of things the person (not the infant) wants to have or know about (Liszkowski et al., 2006, 2008). The account also falls short on the morphological level in explaining the change from a reach with all fingers extended, palm down, to a point with the single index-finger 
extended. Note also that reaches and index-finger points are accompanied by vocalizations of very different prosody (Grünloh \& Liszkowski, 2015). Thus, the ontogenetic ritualization process may explain, if at all, only one aspect of infant pointing, namely the emergence of object-directed requests. The fact that this behavior is present in great apes and children with severely impaired communication (autism syndrome) further supports the interpretation in line with Lock et al. (1990) that ontogenetic ritualization of reaching is on its own not sufficient to account for the emergence of human cooperative, referential-communicative index-finger pointing.

\section{Pointing from non-communicative pointing}

Another version of social shaping suggests that infants first point non-communicatively (Bates et al., 1975). Caregivers then react as if they had been addressed and provide comments and attention. These reactions are somehow rewarding to infants' behavior such that infants then learn to elicit caregivers' reactions by pointing (Moore \& D'Entremont, 2001). The idea is based on the observation that early points appear to lack any communicative accompaniments like vocalizations or gaze alternations with a recipient. However, Bates et al. (1975) also observed that these accompaniments emerged very soon after pointing, within weeks. Prima facie it is perhaps surprising that a few weeks of shaping alone would suffice to transform a behavior. Carpendale and Carpendale (2010) reported diary observations of an infant who touched objects with the index-finger a few months before he began to point communicatively. This increases the developmental time window for shaping to take place, albeit the behavior that would undergo shaping (i.e., touching objects with the index-finger) is very different from Bates' original claim about a non-communicative pointing gesture.

One problem with the account thus lies in step 1 of the shaping sequence, the initial behavior to be shaped. It is not clear exactly what this behavior is, and how infants 
use it. Since absence of evidence is not evidence for absence, the absence of gaze alternation or vocalizations when pointing need not mean an absence of communicative intent (see Liszkowski et al., 2008). Indeed, the reported observations by Carpendale and Carpendale (2010) are open to alternative interpretations invoking communicative rather than non-communicative pointing: In one observation, two weeks after the appearance of the first point, the infant (eleven months, twelve days old; Carpendale \& Carpendale, 2010, p. 119) responds to his father's question where he wants to go by pointing into the direction. It would seem plausible that the infant pointed because of the communicative situation in which it was, to react appropriately to the father's question. Another observation (Carpendale \& Carpendale, 2010, p. 120) reveals that the very first point of a girl at ten months included a look at the caregiver, and the caregiver also interpreted it as communicative (she glossed it in her diary entry as "look at that"), but Carpendale and Carpendale (2010) discard this communicative interpretation. ${ }^{2}$ Clearly, the diary method does meet its limits here, and more details are needed in step 1 of the sequence to first establish the existence of a clearly defined behavior not intended to elicit a caregiver reaction. In addition, we would need to know about infants' systematic use and the function of such behavior; and its own history of origins.

A related problem lies in step 2 of the process. A methodological limitation of diary studies is that there is typically no systematic report of caregivers' reactions (other than caregivers' interpretations). This is problematic when the to-be-shaped behavior bears no obvious meaning at all, like the extension of the single index-finger. What is the common caregiver reaction that would lead infants to subsequently want to elicit that reaction? Index-finger extensions happen in a variety of situations and contexts, during nursing, sleeping, object exploration and so forth (Carpendale \& Carpendale, 2010; Hannan \& Fogel, 1987). Systematic accessible data is missing on whether caregivers systematically attend to it, and react to it in specific ways (see Masataka, 2003, for 
suggestions).

Finally, the account is also vague on step 3 of the process, i.e., the transformation of the usage of the behavior. Even if we had firm evidence that infants initially always point non-communicatively, and even if this was so circumscribed in usage that caregivers would typically react to it by commenting, more details are needed to sketch out why a comment from caregivers should be rewarding to infants, when their goal was to pursue an individual, non-social activity that had nothing to do with the social world. Indeed, it would appear at least equally plausible that caregivers' comments would be distracting. Moore \& d'Entremont (2001; see also Bates et al., 1975) suggested that when infants point, parents allocate extra attention to the infant, and obtaining attention serves as a reward. However, Liszkowski et al. (2004) directly tested this hypothesis and found that attention to the self did not reinforce infants' pointing in any obvious way.

\section{Social shaping accounts-interim conclusion}

We do not propose that caregivers' reactions to infants' behaviors are irrelevant to the development of pointing. Indeed, as we will elaborate later, our conclusion is quite the opposite. But we think that shaping can only play a role if the caregiver reaction is somehow relevant to a goal or function of the infant's behavior. This is clearly the case for reaching. The problem for the reaching account is that the shaping does not change the individual goal into a cooperative or prosocial goal: It does not account for the various underlying intentions of pointing, like sharing attitudes and helpfully providing information for others. For the case of non-communicative pointing, the problem is that an initial goal of this behavior is underspecified - hence it remains unknown how, and which, caregiver reactions could shape a communicative goal from anything. 


\section{Social cognition views}

In contrast to shaping views which need not credit infants with any prior understanding of the behavior they acquire, social cognition views take a social understanding of the behavior to be necessary and causal in its emergence. A common view on the origins of pointing pertains to imitation: infants learn to point by observing and understanding others' point. A related variant holds that gaze-following leads to pointing.

\section{Pointing from imitation}

Infants learn many behaviors through imitating others, and so one proposal is that infants learn pointing through imitation, too (e.g., Tomasello, 1999). An imitation account requires that infants learn to point because they understand what the behavior is for, so that they can use it in that way when they are motivated to do so. Key elements in this process are thus that: 1) infants understand what the pointer is doing with the point-they understand his intention; and 2) infants are motivated to adopt the goal and reproduce pointing to achieve it.

Most imitation research has investigated imitation of goal-directed instrumental actions (Nielsen \& Carpenter, 2008; Matheson, Moore, \& Akhtar, 2013). Understanding and imitating goal-directed instrumental actions, however, is conceptually different from imitating communicative actions. Communicative actions involve multiple interrelated goals, like an intentional relation to a referent and an intentional relation to the recipient (i.e., that she sees the referent; does/feels/thinks something about it; understands that all this is the sender's intention, etc.; Tomasello et al., 2007). In contrast to most goaldirected actions, communicative actions do not produce an immediately observable effect in the environment from the recipient's perspective. It is thus somewhat unclear how infants as observers of pointing could detect the goal, or even the interrelated goals of a 
communicative pointing act just by observing. Empirically, research on the comprehension of pointing has shown that twelve-month-olds do understand the intentionality of pointing on several levels (Liszkowski, 2018, for an overview). However, for it to be predictive of pointing, this understanding would have to emerge before twelve months of age, prior to pointing.

Imitation views of pointing are somewhat unspecific about the conditions of learning, that is, whether infants learn pointing uninvolved from a third-person perspective, or when directly being addressed in second-person engagement. The former case would seem to be more analogous to the imitation of goal-directed actions in that the infant could observe the pointer produce an effect in the recipient and then attempt to reproduce it (see Fawcett \& Liszkowski, 2012). In contrast, in the latter case during second-person engagement, in addition to the difficulties of detecting the goal, the infant needed to somehow reverse goals and understand that what the pointer did to her she can now do to him, and to others (for early forms of role reversal in imitation around twelve months of age; see Carpenter, Tomasello, \& Striano, 2005). The challenge to imitation accounts is thus that infants would first have to understand what a pointer is doing when pointing. This understanding appears rather complex, and it is currently unclear whether a full understanding is available to infants before they begin to point. On the social cognition view, the question about the origins of pointing thus shifts to the question about the development of its underlying cognitive infrastructure.

Our recent studies indeed suggest that the referential comprehension of pointing does not emerge earlier than the production of referential pointing, which thus casts doubts on the social cognition proposal that comprehension of referential pointing leads 
to its production. In a pupillometric study (Pätzold \& Liszkowski, 2019), infants watched a person either point or not point behind a screen, which was then lowered to reveal either an object or an empty site. Only twelve- but not eight-months-olds showed relatively larger pupil dilation to the empty outcome following a point compared to no point, revealing their referential expectation for an object. In a related looking study (Jartó \& Liszkowski, submitted), infants watched an experimenter point to one of two screens behind one of which an object was hidden. When the screens were lowered at test, fourteen- but not eight-month-olds looked longer when the side to which had been pointed was unexpectedly empty compared to when the empty side had not been pointed to, indicating a violation of their referential expectation. Finally, in a behavioral search task (Rüther \& Liszkowski, 2020), from twelve months of age, but not earlier, infants searched reliably above chance for a hidden object in one of two locations, when the experimenter disambiguated the hiding locations through referential pointing. Indeed, the referential expectation of an object was longitudinally predicted by the ability to produce index-finger pointing - it was not predictive of the production of index-finger pointing. Thus, while infants orient attention and follow others' points and gaze cues, it is not before they point that they have the social-cognitive skills to understand the communicative-referential nature of pointing — which would seem a requirement for learning pointing via imitation.

In contrast to complex imitation, a simpler alternative that circumvents the cognitive complexities may be mimicry. Like imitation, mimicry involves copying others; however, the mechanism is rather blind to the goals and intentions, which would suggest that infants blindly mimic their parents when they extend the index-finger and 
point. On its own, mimicry is of course not sufficient to explain the intentional flexible use of pointing at twelve months of age, because on a mimicry account pointing would remain, as it were, pointless.

A further challenge to imitation accounts of pointing is to constrain what exactly infants copy, and what not. For example, caregivers usually vocalize and alternate gaze when pointing — but infants initially don't. Infants initially point with the flat hand before they point with the index-finger (Lock et al., 1990; Liszkowski \& Tomasello, 2011), but they rarely, if ever, see this behavior in their parents' repertoire.

\section{Pointing from gaze-following}

A primary goal of pointing is to direct others' attention. Infants follow others' attention a few months before they begin to point with the index-finger (Carpenter et al., 1998) and this ability may lead to pointing (Butterworth, 2003; Matthews et al., 2012). Perhaps, when caregivers attend to something and point at it, infants then understand that the goal of pointing is to intentionally direct attention. In itself, this would not explain why infants would adopt the goal of directing others' attention, but imitation could be one mechanism. Interestingly, infants would not necessarily need to learn the specific pointing gesture through imitation, but only adopt the goal of directing attention. Theoretically, in the absence of a pointing model, they could still "invent" pointing behavior. Given the body, and best success, arm extension could be the prevailing solution across cultures (Liszkowski et al., 2012). A remaining problem of the gazefollowing account, however, is that on its own it does not explain how the various social intentions underlying pointing emerge. A testable prediction of the gaze-following account would be that when infants point, they want to direct others' attention, but 
initially for no obvious reasons. Experimental studies with twelve-month-old pointing infants, however, contradict this interpretation because the evidence shows that infants have a variety of social intentions, like sharing interest, requesting objects, helping find objects, when they begin to point with the index-finger (Liszkowski, 2018).

\section{Social cognition views - interim conclusion}

Social cognition views derive from the finding that index-finger pointing is underlain by a rich social-cognitive, communicative infrastructure (Tomasello et al., 2007). While we fully agree with this view, our contention is that this infrastructure emerges concurrently with pointing as experimental findings suggest—but it is ontogenetically not predictive of pointing. Instead, additional factors are necessary to construct a social-cognitive understanding from simpler forms of cognitive and attentional processes.

\section{The multifaceted roots of infant pointing}

The ontogenetic roots of pointing are multifaceted, and in one or another way the accounts reviewed above all carry an element of truth in them. Here we offer a synthesis, supported by new findings we have recently obtained in longitudinal studies in our lab (Rüther \& Liszkowski, submitted). Both social environment and cognitive processes undoubtedly play a role in the emergence of pointing. We assume that both child and caregiver levels are interlocked from the beginning and transform each other rather continuously from early on. Any predictor of infant pointing thus begs the question about its own predictor. We thus have to work our way backwards to unravel the various roots of pointing, and how they interact in development. In doing so, we are looking at a developmental principle in which social interaction both transforms and adapts to its cognition. 
Regarding caregiver behavior, we claim that it is initially effective as a reaction to infants' behaviors, but only if the reaction is relevant to infants' activity. For example, as we saw, responding referentially to infants' referential pointing increases infants' frequency of pointing in development (Ger et al., 2018), presumably because parents' referential response fulfills infants' referential goal when pointing. In our new lab-based investigations, we have looked at infants before they point (Rüther \& Liszkowski, submitted). Using a longitudinal design with monthly assessments from eight to thirteen months (using the "decorated room" method; Liszkowski et al., 2012), we found that parent pointing at eight months of infant age significantly predicts the age of emergence of index-finger pointing. Further, we found that parents of six-month-olds point significantly less than parents of eight-month-olds. Why would parent pointing begin at a specific developmental age? We think the answer is that caregivers' pointing is not so much a modeling behavior but rather a response to developmentally earlier infant behaviors. The claim is thus that parents begin to point for their infants once they assume that their infants can make use of their point.

Regarding infant behavior, in our view the social influence is thus only effective once infants have the skills and capacities to understand and engage with it, and when it is relevant to their goals. In support, we found in our longitudinal study that infants' showing gestures at nine months are predictive of the age of emergence of index-finger pointing. Likely, then, infants' referential goal is already present before they begin to point. Further, we found that point-following at nine months is predictive of the age of emergence of index-finger pointing (see also Matthews et al., 2012). In our study, pointfollowing is not longitudinally predicted by parent pointing suggesting that parents' 
pointing is indeed rather a response to infants' emerged ability to follow others' attentional focus. In order to understand the ontogenetic roots of pointing, we thus need to reverse engineer ontogeny: What predicts parents' pointing? What predicts infants' attention following? What predicts infants' showing gestures?

In our view, the key element in the developmental process is that parents' interactional behaviors are responsive and relevant to a goal that infants pursue. This must mean that a starting state of the entire developmental process of pointing is infants' directedness toward a however-crudely represented goal. What are these goals that parents' responsiveness may be relevant for? We distinguish between goals that lead to individual activity and are inherently motivated by self-related activities; and goals that lead to joint activity based on a deeply social motivation to relate to others. Regarding the former, in the case of reaching, the individual self-related goal of obtaining an object may be shaped to using communicative means for achieving it (Vygotsky, 1962). However, as we have discussed before, individual goal pursuit will not shape up to a cooperative and prosocially motivated use of communicative pointing (e.g., declarative expressive pointing). Instead, we thus argue that the cooperative prosocial forms of infant pointing rest on goals entrenched in and derived from social situations: social goals. These latter, social goals built on infants' directedness of behavior and infants' uniquely deep social motivation to orient toward other social beings. They derive from interaction routines, in which parents create formats of mutual object manipulation and transposition.

To exemplify, in "give-and-take" routines which are at first established during feeding (and then culturally canalized toy play), parents offer an item for infants to take, infants' attention gets directed toward the item, and infants' directed behavior leads 
infants to accept or reject it. Infants' behavior, in turn, leads parents to take the item or offer another. The key distinguishing feature between simple object transpositions and "give-and-take" interactions of this kind is that in the latter case, the more infants" activity becomes directed toward the environment, leading them to accept and reject objects around them, the more will caregivers' assistance involve treating objects as referents of potential choice. The mutual give-and-take thus turns into incorporating offers (“want this?”) and requests (“want that!”) which refer to potential objects of transpositions before the objects are transposed (or not). These social transactions transform "objects of action" into "objects of regard" in situations of an "undifferentiated We" (Werner \& Kaplan, 1963), in which roles are initially undifferentiated and exchangeable and become increasingly differentiated through further variation in socialinteractive experience. From this perspective, infants' reaching gestures stem from utterly social situations, not from individual problem-solving attempts: they derive from accepting offers and preparing to receive offered items in social settings; and not from failed attempts of grasping unreachable items during individual problem solving. Similarly, infants' gives, and then offers and show gestures derive from the distributed activity of selecting and deselecting objects in shared social formats like give-and-take. Parent pointing then emerges as a reaction to infants' interest in possible referents. It is predictive of infant pointing, because the goal of infant pointing derives from the earlier social matrix of object transpositions and mutual treating of objects as referents of potential choice. Parent-infant pointing thus viewed is not the beginning of a long chain of shaping individual activity into joint activity—instead, it is the outcome of earlier forms of joint activity with its transformative quality (see Figure 31.4 for an illustration). 


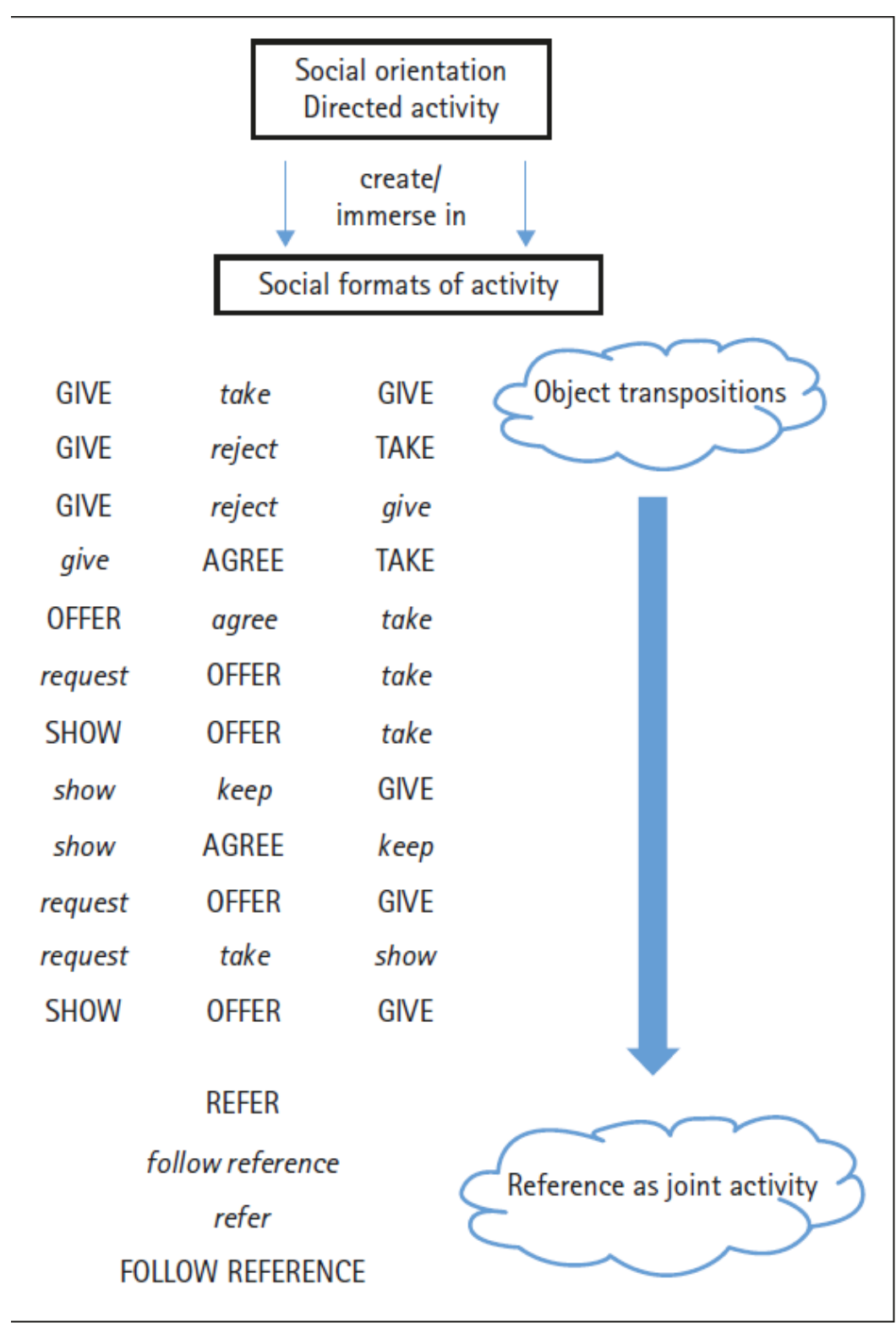

Figure 31.4:

Illustration of the transformative development from transposing objects to referring to objects in joint activity. The starting point is a deep social motivation paired with directed activity that yields social formats and creates social goals. Each row displays a three-turn interaction with objects. Caregivers' turns are capitalized; infants' turns are italicized. Successive rows capture variation in the reiterative process of turn-taking over developmental time. 


\section{Summary}

We have argued that the emergence of infant index-finger pointing as a foundation for language acquisition and further cultural learning is best explained from a socialconstructivist perspective. Caregiver-child interactions in the first year of life transform earlier behaviors and social goals into communicative exchanges with referential pointing gestures. A thoroughgoing social-constructivist perspective on the ontogeny of pointing embraces both social cognition accounts and social shaping accounts. Social cognition accounts typically treat social understanding as an explanatory mechanism of pointing. A thoroughgoing social-constructivist perspective, however, also needs to account for the emergence of social understanding that underlies pointing. Social shaping accounts view caregiver behaviors as the driving force of development. The social-constructivist perspective emphasizes in addition the importance of cognitive processes inside the child for shaping to take place. Specifically, we hold that infants' directedness is a necessary requirement for relevant caregiver behaviors to exert an effect, and we emphasize that this directedness must be social in nature to begin with, in order to then arrive at a cooperative usage of infant pointing. Apart from infant directedness and caregiver responsiveness, the rock bottom of our account is then the deep social orientation of infants and their caregivers toward each other, which is so unique to the human species (Leary \& Baumeister, 2017; Tomasello, 2014; Trevarthen, 1979). We assume that this social motivation emerged as an adaptation in humans, to enable cooperation and/or secure attachment (Hrdy, 2009; Tomasello \& Gonzalez-Cabrera, 2017). This social motivation paired with directed behavior yields some rudimentary form of togetherness 
in directed social activities, which is from the beginning altogether different from individual object-oriented reality. It scales up to create a shared reality which lends itself to the emergence and coordinating use of pointing acts as a foundation for constructing social reality.

\section{Acknowledgment}

The current chapter was supported by the German Federal Ministry of Education and Research (BMBF, grant number 01DL14007).

\section{References}

Baron-Cohen, S. (1989). Joint-attention deficits in autism: Towards a cognitive analysis. Development and Psychopathology 1, 185-189. doi.org/10.1017/S0954579400000377

Bates, E. (1979). The emergence of symbols: Cognition and communication in infancy. Burlington: Academic Press.

Bates, E., Camaioni, L., \& Volterra, V. (1975). The acquisition of performatives prior to speech. Merrill-Palmer Quarterly of Behavior and Development 21(3), 205-226. Retrieved from https://www.jstor.org/stable/23084619

Behne, T., Liszkowski, U., Carpenter, M., \& Tomasello, M. (2012). Twelve-month-olds' comprehension and production of pointing. The British Journal of Developmental Psychology 30(Pt 3), 359-375. doi.org/10.1111/j.2044-835X.2011.02043.x

Blake, J., O’Rourke, P., \& Borzellino, G. (1994). Form and function in the development of pointing and reaching gestures. Infant Behavior and Development 17, 195-203. doi.org/10.1016/0163-6383(94)90055-8 
Boundy, L., Cameron-Faulkner, T., \& Theakston, A. (2016). Exploring early communicative behaviours: A fine-grained analysis of infant shows and gives. Infant Behavior and Development 44, 86-97. doi.org/10.1016/j.infbeh.2016.06.005

Brink, I. (2004). Joint attention, triangulation and radical interpretation: A problem and its solution. Dialectica 58(2), 179-206. doi.org/10.1111/j.17468361.2004.tb00296.x

Brooks, R., \& Meltzoff, A. N. (2002). The importance of eyes: How infants interpret adult looking behavior. Developmental Psychology 38(6), 958. doi.org/10.1037/0012-1649.38.6.958

Bruner, J. S. (1975). The ontogenesis of speech acts. Journal of Child Language 2, 1-19. doi.org/10.1017/S0305000900000866

Bruner, J. S. (1983). Child's talk. New York: Norton.

Butterworth, G., \& Itakura, S. (1998). Development of precision grips in chimpanzees. Developmental Science 1(1), 39-43. doi.org/10.1111/1467-7687.00010

Butterworth, G., \& Morissette, P. (1996). Onset of pointing and the acquisition of language in infancy. Journal of Reproductive and Infant Psychology 14(3), 219231. doi.org/10.1080/02646839608404519

Butterworth, G. (2003). Pointing is the royal road to language for babies. In S. Kita (Ed.), Pointing: Where language, culture, and cognition meet (pp. 9-33). Mahwah, NJ: Erlbaum Associates. 
Call, J., \& Tomasello, M. (1994). Production and comprehension of referential pointing by orangutans (Pongo pygmaeus). Journal of Comparative Psychology 108(4), 307. doi.org/10.1037/0735-7036.108.4.307

Camaioni, L. (1993). The social construction of meaning in early infant-parent and infant-peer relations. In J. Nadel \& L. Camaioni (Eds.), New perspectives in early communicative development (234-259). London: Routledge.

Cameron-Faulkner, T., Theakston, A., Lieven, E., \& Tomasello, M. (2015). The relationship between infant holdout and gives, and pointing. Infancy 20(5), 576586. doi.org/10.1111/infa.12085

Capirci, O., Iverson, J. M., Pizzuto, E., \& Volterra, V. (1996). Gestures and words during the transition to two-word speech. Journal of Child Language 23(3), 645-673. doi.org/10.1017/S0305000900008989

Carpendale, J. I., Atwood, S., \& Kettner, V. (2013). Meaning and mind from the perspective of dualist versus relational worldviews: Implications for the development of pointing gestures. Human Development 56(6), 381-400. doi.org/10.1159/000357235

Carpendale, J. I., \& Carpendale, A. B. (2010). The development of pointing: From personal directedness to interpersonal direction. Human Development 53(3), 110126. doi.org/10.1159/000315168

Carpenter, M., Nagell, K., Tomasello, M., Butterworth, G., \& Moore, C. (1998). Social cognition, joint attention, and communicative competence from 9 to 15 months of age. Monographs of the Society for Research in Child Development 63(4), 1-174. doi: $10.2307 / 1166214$ 
Carpenter, M., Tomasello, M., \& Striano, T. (2005). Role reversal imitation and language in typically developing infants and children with autism. Infancy 8(3), 253-278. doi.org/10.1207/s15327078in0803_4

Chang, L., de Barbaro, K., \& Deák, G. (2016). Contingencies between infants' gaze, vocal, and manual actions and mothers' object-naming: Longitudinal changes from 4 to 9 months. Developmental Neuropsychology 41(5-8), 342-361. doi.org/10.1080/87565641.2016.1274313

D’Entremont, B., Hains, S. M. J., \& Muir, D. W. (1997). A demonstration of gaze following in 3-to 6-month-olds. Infant Behavior and Development 20(4), 569572. doi.org/10.1016/S0163-6383(97)90048-5

Enfield, N. J. (2001). "Lip-pointing": A discussion of form and function with reference to data from Laos. Gesture 1(2), 185-211. doi.org/10.1075/gest.1.2.06enf

Esteve-Gibert, N., \& Prieto, P. (2013). Prosody signals the emergence of intentional communication in the first year of life: Evidence from Catalan-babbling infants. Journal of Child Language 40(5), 919-944.

doi.org/10.1017/S0305000912000359

Fawcett, C., \& Liszkowski, U. (2012). Mimicry and play initiation in 18-month-old infants. Infant Behavior and Development 35(4), 689-696. doi.org/10.1016/j.infbeh.2012.07.014

Franco, F., \& Butterworth, G. (1996). Pointing and social awareness: Declaring and requesting in the second year. Journal of Child Language 23(02), 1. doi.org/10.1017/S0305000900008813 
Ger, E., Altıntok, N., Liszkowski, U., \& Küntay, A. C. (2018). Development of infant pointing from 10 to 12 months: The role of relevant caregiver responsiveness. Infancy 21(1), 205. doi.org/10.1111/infa.12239

Goldstein, M. H., \& Schwade, J. A. (2008). Social feedback to infants' babbling facilitates rapid phonological learning. Psychological Science 19(5), 515-523. doi.org/10.1111/j.1467-9280.2008.02117.x

Grünloh, T., \& Liszkowski, U. (2015). Prelinguistic vocalizations distinguish pointing acts. Journal of Child Language 42(6), 1312-1336. doi.org/10.1017/S0305000914000816

Hannan, T. E., \& Fogel, A. (1987). A case-study assessment of "pointing" during the first three months of life. Perceptual and Motor Skills 65(1), 187-194. doi.org/10.2466/pms.1987.65.1.187

Hay, D. F., \& Murray, P. (1982). Giving and requesting: Social facilitation of infants' offers to adults. Infant Behavior and Development 5(2-4), 301-310. doi.org/10.1016/S0163-6383(82)80039-8

Hopkins, W. D., Cantalupo, C., Wesley, M. J., Hostetter, A. B., \& Pilcher, D. L. (2002). Grip morphology and hand use in chimpanzees (Pan troglodytes): Evidence of a left hemisphere specialization in motor skill. Journal of Experimental Psychology: General 131(3), 412. doi.org/10.1037/0096-3445.131.3.412

Hrdy, S. (2009). Mothers and others: The evolutionary origins of mutual understanding. Cambridge, MA: Harvard University Press. 
Iverson, J. M., \& Goldin-Meadow, S. (2001). The resilience of gesture in talk: Gesture in blind speakers and listeners. Developmental Science 4(4), 416-422. doi.org/10.1111/1467-7687.00183

Iverson, J. M., \& Goldin-Meadow, S. (2005). Gesture paves the way for language development. Psychological Science 16(5), 367-371. doi.org/10.1111/j.09567976.2005.01542.x

Jartó, M. \& Liszkowski, U. (submitted). Inferring hidden objects from still and communicative onlookers at 8-, 14- and 36-months of age. Manuscript submitted for publication.

Kishimoto, T. (2017). Cross-sectional and longitudinal observations of pointing gestures by infants and their caregivers in Japan. Cognitive Development 43, 235-244. doi.org/10.1016/j.cogdev.2017.06.001

Kishimoto, T., Shizawa, Y., Yasuda, J., Hinobayashi, T., \& Minami, T. (2007). Do pointing gestures by infants provoke comments from adults? Infant Behavior and Development 30(4), 562-567. doi.org/10.1016/j.infbeh.2007.04.001

Leary, M. R., \& Baumeister, R. F. (2017). The need to belong: Desire for interpersonal attachments as a fundamental human motivation. In R. Zukauskiene (Ed.), Interpersonal Development (pp. 57-89). London: Routledge.

Leavens, D. A., Ely, J., Hopkins, W. D., \& Bard, K. A. (2012). Effects of cage mesh on pointing: Hand shapes in chimpanzees (Pan troglodytes). Animal Cognition 15(3), 437-441. doi.org/10.1007/s10071-011-0466-6 
Leavens, D. A., \& Hopkins, W. D. (1999). The whole-hand point. The structure and function of pointing from a comparative perspective. Journal of Comparative Psychology 113(4), 417-425. doi.org/10.1037/0735-7036.113.4.417

Leavens, D. A., Reamer, L. A., Mareno, M. C., Russell, J. L., Wilson, D., Schapiro, S. J., \& Hopkins, W. D. (2015). Distal communication by chimpanzees (Pan troglodytes): Evidence for common ground? Child Development 86(5), 16231638. doi.org/10.1111/cdev.12404

Leung, E. H. L., \& Rheingold, H. L. (1981). Development of pointing as a social gesture. Developmental Psychology 17(2), 213-230. doi.org/10.1037/0012-1649.17.2.215

Liszkowski, U. (2018). Origins and complexities of infant communication and social cognition. In A. Newen, L. D. Bruin \& S. Gallagher (Eds.), Oxford handbook of cognition: Embodied, embedded, enactive and extended (pp. 661-684). Oxford: Oxford University Press.

Liszkowski, U., Brown, P., Callaghan, T., Takada, A., \& de Vos, C. (2012). A prelinguistic gestural universal of human communication. Cognitive Science 36(4), 698-713. doi.org/10.1111/j.1551-6709.2011.01228.x

Liszkowski, U., Carpenter, M., Henning, A., Striano, T., \& Tomasello, M. (2004). Twelve-month-olds point to share attention and interest. Developmental Science 7(3), 297-307. doi.org/10.1111/j.1467-7687.2004.00349.x

Liszkowski, U., Carpenter, M., Striano, T., \& Tomasello, M. (2006). 12- and 18-montholds point to provide information for others. Journal of Cognition and Development 7(2), 173-187. doi.org/10.1207/s15327647jcd0702_2 
Liszkowski, U., Carpenter, M., \& Tomasello, M. (2007a). Pointing out new news, old news, and absent referents at 12 months of age. Developmental Science 10(2), 7. doi.org/10.1111/j.1467-7687.2006.00552.x

Liszkowski, U., Carpenter, M., \& Tomasello, M. (2007b). Reference and attitude in infant pointing. Journal of Child Language 34(01), 1. doi.org/10.1017/S0305000906007689

Liszkowski, U., Carpenter, M., \& Tomasello, M. (2008). Twelve-month-olds communicate helpfully and appropriately for knowledgeable and ignorant partners. Cognition 108(3), 732-739. doi.org/10.1016/j.cognition.2008.06.013

Liszkowski, U., \& Tomasello, M. (2011). Individual differences in social, cognitive, and morphological aspects of infant pointing. Cognitive Development 26(1), 16-29. doi.org/10.1016/j.cogdev.2010.10.001

Lobo, M. A., \& Galloway, J. C. (2013). The onset of reaching significantly impacts how infants explore both objects and their bodies. Infant Behavior and Development 36(1), 14-24. doi.org/10.1016/j.infbeh.2012.09.003

Lock, A., Young, A., Service, P., \& Chandler, P. (1990). Some observations on the origins of the pointing gesture. In V. Volterra \& C. J. Erting (Eds.), From gesture to language in hearing and deaf children (pp. 42-55). New York: SpringerVerlag.

Lüke, C., Grimminger, A., Rohlfing, K. J., Liszkowski, U., \& Ritterfeld, U. (2016). In infants' hands: Identification of preverbal infants at risk for primary language delay. Child Development 58(2), 484-492. doi.org/10.1111/cdev.12610 
Marcos, H. (1991). How adults contribute to the development of early referential communication? European Journal of Psychology of Education 6(3), 271. doi.org/10.1007/BF03173150

Masataka, N. (2003). From index-finger extension to index-finger pointing: Ontogenesis of pointing in preverbal infants. . In S. Kita (Ed.), Pointing: Where language, culture, and cognition meet (pp. 69-84). Mahwah, NJ: Erlbaum Associates.

Matheson, H., Moore, C., \& Akhtar, N. (2013). The development of social learning in interactive and observational contexts. Journal of Experimental Child Psychology 114(2), 161-172. doi.org/10.1016/j.jecp.2012.09.003

Matthews, D., Behne, T., Lieven, E., \& Tomasello, M. (2012). Origins of the human pointing gesture: A training study. Developmental Science 15(6), 817-829. doi.org/10.1111/j.1467-7687.2012.01181.x

Messinger, D. S., \& Fogel, A. (1998). Give and take: The development of conventional infant gestures. Merrill-Palmer Quarterly (1982-) 44(4), 566-590. Retrieved from http://www.jstor.org/stable/23093754

Moore, C., \& d'Entremont, B. (2001). Developmental changes in pointing as a function of attentional focus. Journal of Cognition and Development 2(2), 109-129. doi.org/10.1207/S15327647JCD0202_1

Murphy, C. M. (1978). Pointing in the context of a shared activity. Child Development 49(2), 371-380. doi: $10.2307 / 1128700$

Nielsen, M., \& Carpenter, M.(2008). Tools, TV, and trust: Introduction to the special issue on imitation in typically-developing children. Journal of Experimental Child Psychology 101(4), 225-227. doi.org/10.1016/j.jecp.2008.09.005 
O’Madagain, C., Kachel, G., \& Strickland, B. (2019). The origin of pointing: Evidence for the touch hypothesis. Science advances 5(7), eaav2558.

Pätzold, W., \& Liszkowski, U. (2019). Pupillometry reveals communication-induced object expectations in 12-but not 8-month-old infants. Developmental science 22(6), e12832.

Puccini, D., Hassemer, M., Salomo, D., \& Liszkowski, U. (2010). The type of shared activity shapes caregiver and infant communication. Gesture 10(2-3), 279-296.

Ramenzoni, V. C., \& Liszkowski, U. (2016). The social reach: 8-month-olds reach for unobtainable objects in the presence of another person. Psychological Science 27(9), 1278-1285. doi.org/10.1177/0956797616659938

Reilly, S., Eadie, P., Bavin, E. L., Wake, M., Prior, M., Williams, J., Bretherton, L., Barrett, Y., \& Ukoumunne, O. C. (2006). Growth of infant communication between 8 and 12 months: a population study. Journal of Paediatrics and Child Health 42(12), 764-770. doi.org/10.1111/j.1440-1754.2006.00974.x

Renzi, D. T., Romberg, A. R., Bolger, D. J., \& Newman, R. S. (2017). Two minds are better than one: Cooperative communication as a new framework for understanding infant language learning. Translational Issues in Psychological Science 3(1), 19-33. doi.org/10.1037/tps0000088

Rochat, P., Goubet, N., \& Senders, S. J. (1999). To reach or not to reach? Perception of body effectivities by young infants. Infant and Child Development 8(3), 129-148. doi.org/10.1002/(SICI)1522-7219(199909)8:3<129::AID-ICD193>3.0.CO;2-G 
Rönnqvist, L., \& Hofsten, C. von. (1994). Neonatal finger and arm movements as determined by a social and an object context. Early Development and Parenting 3(2), 81-94. doi.org/10.1002/edp.2430030205

Rowe, M. L., \& Goldin-Meadow, S. (2009). Differences in early gesture explain SES disparities in child vocabulary size at school entry. Science 323(5916), 951-953. doi.org/10.1126/science.1167025

Rowe, M. L., \& Leech, K. A. (2018). A parent intervention with a growth mindset approach improves children's early gesture and vocabulary development. Developmental Science 22(4), e12792. doi.org/10.1111/desc.12792

Rüther, J., \& Liszkowski, U. (2020). Ontogenetic emergence of cognitive reference comprehension. Cognitive Science 44(7), e12869.

Rüther, J., \& Liszkowski, U. (submitted). Ontogeny of Index-finger Pointing. Manuscript submitted for publication.

Salomo, D., \& Liszkowski, U. (2013). Sociocultural settings influence the emergence of prelinguistic deictic gestures. Child Development 84(4), 1296-1307. doi.org/10.1111/cdev.12026

Sodian, B., \& Kristen-Antonow, S. (2015). Declarative joint attention as a foundation of theory of mind. Developmental Psychology 51(9), 1190-1200. doi.org/10.1037/dev0000039

Sperber, D., \& Wilson, D. (1986). Relevance: Cognition and communication. Oxford: Blackwell.

Tomasello, M. (1999). The cultural origins of human cognition. Cambridge, MA: Harvard University Press. 
Tomasello, M. (2006). Why don't apes point? In N. J. Enfield \& S. C. Levinson (Eds.), Roots of human sociality: Culture, cognition, and interaction (pp. 506-524). Oxford: Berg.

Tomasello, M. (2014). A natural history of human thinking. Cambridge, MA: Harvard University Press.

Tomasello, M., Hare, B., Lehman, H., \& Call, J. (2007). Reliance on head versus eyes in the gaze following of great apes and human infants: The cooperative eye hypothesis. Journal of Human Evolution 52(3), 314-320. doi.org/10.1016/j.jhevol.2006.10.001

Tomasello, M., Carpenter, M., \& Liszkowski, U. (2007). A new look at infant pointing. Child Development 78(3), 705-722. doi.org/10.1111/j.1467-8624.2007.01025.x Tomasello, M., \& Gonzalez-Cabrera, I. (2017). The role of ontogeny in the evolution of human cooperation. Human Nature 28(3), 274-288. doi.org/10.1007/s12110-017$9291-1$

Trevarthen, C. (1979). Communication and cooperation in early infancy: A description of primary intersubjectivity. In M. M. Bullowa (Ed.), Before speech: The beginning of interpersonal communication (pp. 321-349). Cambridge: Cambridge University Press.

van der Goot, M. H,. Tomasello, M., \& Liszkowski, U. (2014). Differences in the nonverbal requests of great apes and human infants. Child Development 85(2), 444-455. doi.org/10.1111/cdev.12141

Vygotsky, L. S. (1978). Mind in society: The development of higher psychological processes. Cambridge, MA: Harvard University Press. 
Vygotsky, L. S. (1962). Language and thought. Ontario: MIT Press.

Werner, H., \& Kaplan, B. (1963). Symbol formation: An organismic-developmental approach to language and the expression of thought. New York: Wiley.

Wu, Z., \& Gros-Louis, J. (2014). Infants' prelinguistic communicative acts and maternal responses: Relations to linguistic development. First Language 34(1), 72-90. doi.org/10.1177/0142723714521925

Figure 31.1:

Index-finger extension at six months of age in a dyadic face-to-face situation.

Figure 31.2:

Video still-frames showing a mother with her thirteen-month-old infant during the joint activity of looking together at decoration items. Left panel: infant index-finger pointing; right panel: infant whole-hand pointing.

${ }^{1}$ Leavens et al. (2015) provide photographs of captive apes who extend their arms unsupported, presumably while begging for distal items outside their enclosure (presumably food). The hand shape is clearly different from canonical distal index-finger pointing in human infants and adults, and the items cannot be obtained by the apes themselves.

${ }^{2}$ Carpendale \& Carpendale (2010, p. 120): “ . . . it is possible that Madeline’s pointing was a manifestation of her own directedness toward the object she had dropped, and she then simply looked toward her mother, perhaps because her mother may have picked things up in the past." 